\title{
TRIBUNAL CONSTITUCIONAL Y POSITIVISMO JURÍDICO
}

\author{
Luis Prieto Sanchís \\ Universidad de Castilla-La Mancha
}

\section{Introducción. Algunas objeciones, no necesariamente positivistas, a la Justicia Constitucional.}

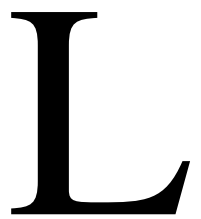

a expresión positivismo jurídico suele usarse con una cierta imprecisión para designar tesis a propósito del Derecho no sólo heterogéneas, sino abiertamente contradictorias ${ }^{1}$. A mi juicio, las tesis más valiosas y que merecen ser conservadas no tienen mucho que ver con la existencia de alguna forma de justicia constitucional: ni la idea de las fuentes sociales del Derecho, ni la que postula la separación conceptual entre el Derecho y la moral, ni, en fin, aquella que vincula el Derecho con la fuerza se resienten o fortalecen por la existencia o no de Tribunales Constitucionales ${ }^{2}$. Mayores problemas presenta la tesis de la discreción judicial que, si bien no es intrínseca a todo positivismo, sí ha sido sostenida en sus versiones más maduras, como las representadas por Kelsen, Hart o Ross ${ }^{3}$. Mi conclusión será también negativa, en el sentido de rechazar una implicación necesaria entre la justicia constitucional y la existencia o no de discreción, pero aquí la respuesta requiere una explicación más detenida, pues, como veremos, el género de interpretación que reclaman las Constituciones actuales pone sobre la mesa una serie de técnicas y argumentos ajenos a la tradición positivista.

${ }^{1}$ He tratado este asunto en Constitucionalismo y positivismo, Fontamara, México, 1997, pp.11 y ss., pero para su mejor conocimiento son esclarecedores los estudios de N. Bobbio, entre ellos, Giusnaturalismo e positivismo giuridico, Ed. di Comunità, Milano, 30ed., 1977, en especial pp. 101 y ss.

${ }^{2}$ Ya sé que algunos no estarán de acuerdo con esta posición, sugiriendo que la interpretación constitucional es el vehículo mediante el que necesariamente penetra la moral en el Derecho, pero no me ocuparé aquí de esta cuestión. De nuevo me remito al libro citado en nota precedente, pp. 49 y ss.; también A. García Figueroa, Principios y positivismo jurídico, C.E.C., Madrid, 1998, pp. 327 y ss.

${ }^{3}$ Me remito aquí al libro de I. Lifante, La interpretación jurídica en la teoría del Derecho contemporánea, C.E.P.C., Madrid, 1999. 
Con todo, a primera vista, si hay algún aspecto del positivismo que aparezca claramente lesionado por la justicia constitucional, éste es el conocido con el nombre de legalismo, esto es, aquella tesis que hace de la ley la única o en todo caso la suprema fuente del Derecho ${ }^{4}$. No obstante, el legalismo puede ser entendio de dos formas: primero, como una afirmación descriptiva de teoría del Derecho y, en este sentido, será verdadera o falsa según sea el sistema jurídico que pretenda describir; por ejemplo, creo que el legalismo que se desarrolla en la ciencia jurídica europea a lo largo del siglo XIX es sustancialmente acertado y que, en cambio, el que hoy pudiera sostenerse resultaría equivocado por la elemental razón, entre otras, de que existe un modelo constitucional garantizado. Pero, en segundo lugar, el legalismo puede ser entendido como una posición de política jurídica o de filosofía política, esto es, como una proposición prescriptiva que postula la soberanía de la ley por reunir ésta una serie de condiciones que la hacen legítima, en particular su fundamento democrático. Me parece dudoso que, concebido en esta segunda acepción, el legalismo sea una tesis positivista, pero en cualquier caso es aquí donde aparece el conflicto entre la Constitución normativa o la justicia constitucional y las prerrogativas del legislador. El nucleo de la cuestón es fácil de adivinar: si la ley es la expresión de la voluntad general y ésta «no puede enajenarse jamás» ${ }^{5}$, ¿en nombre de qué las generaciones pasadas pueden atar a las generaciones futuras?, ¿qué legitimidad ostenta un cuerpo judicial para limitar o someter a las mayorías parlamentarias?, ¿cómo la decisión democrática puede ser interferida por quienes no representan a nadie?.

Estas son antiguas objeciones constantemente renovadas que encierran en sí el nucleo fundamental del problema constitucional y de sus garantías ${ }^{6}$. Como es lógico, no procede aquí reproducir las innumerables aportaciones al debate, últimamente acentuado con los nuevos argumentos de J. Waldron $^{7}$. A título de ejemplo, creo que será suficiente con dar sucinta noticia

${ }^{4}$ Vid., por ejemplo, N. Bobbio, Il positivismo giuridico, Giappichelli, Torino, 1979, pp. 189 y ss.

${ }^{5}$ J.J. Rousseau, El contrato social (1762), en Escritos de combate, trad. de G, Masó, Alfaguara, Madrid, 1979, Libro II, I, p.421. Aquí conviene hacer una «pequeña» abstración de las diferencias que separan la democracia rousseauniana de la práctica política de nuestra democracia parlamentaria, pero es indispensable para seguir adelante.

${ }^{6}$ Una aproximación histórica en S. Holmes, «Precommitment and the Paradox of Democracy», en J. Elster y R. Slagstad (eds.) Constitutionalism and Democracy, Cambridge University Press, Mass., pp.195 y ss.

${ }^{7}$ J. Waldron, «A Right-Based Critique of Constitutional Rights», en Oxford Journal of Legal Studies, ${ }^{\circ}$ 13, 1, 1993, pp. 18 y ss. Desde una perspectiva crítica hacia la justicia constitucional y también con un interesante enfoque histórico de la cuestión vid., R. Gargarella, La justicia frente al gobierno. Sobre el carácter contramayoritario del poder judicial, Ariel, 
de una posición interesante al menos por dos motivos: porque aparece en una de las obras de filosofía jurídica y política más citadas de esta década $\mathrm{y}$, sobre todo, porque expresa un punto de vista abiertamente legalista y democrático donde, sin embrago, parece tener cabida alguna forma de justicia constitucional. Me refiero al libro de Habermas, Facticidad y validez.

De entrada, es evidente que el autor alemán muestra poco entusiasmo por la justicia constitucional, lo que no deja de ser comprensible: en la tensión entre los derechos y la democracia, o también entre una concepción liberal y una republicana de la comunidad política, quienes se sitúan en posiciones más próximas a la primera de las alternativas enunciadas suelen mirar con simpatía el establecimiento de restricciones al principio de mayorías en nombre de la autonomía y de las libertades del individuo, mientras quienes, como Habermas, prefieren la segunda de esas alternativas tienden a subrayar los aspectos de legitimidad vinculados al sistema democrático de producción de las leyes, postergando las formas de control. Así, tras reconocer que un Tribunal Constitucional no tiene más remedio que proceder a interpretaciones constructivas, Habermas añade que «una concepción procedimental del derecho obligaría (al T.C.) a un papel más bien restrictivo» ${ }^{9}$. En concreto, si bien el recurso de amparo y la cuestión de inconstitucionalidad resultan poco problemáticos -afirmación que, como veremos, no deja de ser sorprendente desde una perspectiva kelseniana-, el control abstracto de leyes supone una inaceptable colisión entre el Tribunal y las prerrogativas del legislador, entre un cuerpo elitista y contramayoritario y la decisión legítima de la soberanía popular: «lo que se llama control abstracto (sin referencia a un caso concreto) pertenece incuestionablemente a las funciones del legislador». La solución es la que cabría esperar y no puede decirse que represente un alarde de originalidad: el autocontrol del legislador, organizado «a modo de tribunal, e institucionalizándolo, por ejemplo, en una comisión parlamentaria», algo que -no sé muy bien por qué- incluso «contribuiría quizá a aumentar la racionalidad del proceso de producción legislativa ${ }^{10}$. Como veremos, no muy distinta era la posición del Kelsen cuando situaba la justicia constitucional en la esfera de la legislación, no de

Barcelona, 1996. Vid. asimismo algunos de los planteamientos más recientes en P. De Lora Deltoro, La interpretación originalista de la Constitución, C.E.P.C., Madrid, 1999, pp. 55 y ss.; y en el volumen 10 de Ragion Pratica «Discutendo di democrazia», con aportaciones de J.J. Moreso, J.C. Bayón, R. Gargarella, A. Guibourg y E. Vitale; también el libro de V. Ferreres, Justicia constitucional y democracia, C.E.C., Madrid, 1997.

${ }^{8}$ Introducción y traducción de la cuarta edición revisada de Manuel Jiménez Redondo, Trotta, Madrid, 1998.

${ }^{9}$ J. Habermas, Facticidad y validez, citado, p.525.

${ }^{10}$ Ibidem, p. 314 y s. 
la jurisdicción; y, si bien se mira, tampoco es muy diferente la posición de un Tribunal Constitucional como el español, elegido directa o indirectamente por el propio Parlamento que ha de ser controlado.

Sin embargo, la crítica habermasiana no se dirige tanto a las competencias que desempeña el Tribunal Constitucional, cuanto más bien a la autocomprensión que éste tiene de su labor y de los métodos o técnicas que utiliza para resolver los casos. En particular, la censura se centra en uno de los más celebrados hallazgos de la moderna jurisprudencia constitucional cual es la ponderación de bienes como forma de encarar los conflictos entre derechos o principios constitucionales. Haciéndose eco de toda una literatura jurídica que identifica ponderación con libre creación, entiende que la consideración de los derechos fundamentales como bienes o valores que han de ser ponderados en el caso concreto convierte al Tribunal en un negociador de valores, en una «instancia autoritaria» que invade las competancias del legislador y que «aumenta el peligro de juicios irracionales porque con ello cobran primacía los argumentos funcionalistas a costa de los argumentos normativos» ${ }^{11}$. La alternativa para un tratamiento racional del recurso de amparo consiste en una argumentación deontológica que sólo permita para cada caso una única solución correcta, lo que implica concebir los derechos como auténticos principios, no como valores que pueden ser ponderados en un razonamiento teleológico; se trata, en suma, de «hallar entre las normas aplicables prima facie aquella que se acomoda mejor a la situación de aplicación, descrita de la forma más exhaustiva posibles desde todos los puntos de vista» ${ }^{12}$.

Y es que, para Habermas, la coherencia sistemática que se predica de las normas constitucionales en el plano de su validez parece que puede prolongarse racionalmente en el plano de la aplicación, y por ello un principio no puede tener más o menos peso, sino que será adecuado o inadecuado para regular el caso concreto, y siempre habrá uno más adecuado ${ }^{13}$. Si no me equivoco, este enfoque encuentra su paralelismo en la dogmática de los de-

${ }^{11}$ Ibidem, p. 332.

${ }^{12}$ Ibidem, p. 333.

${ }^{13}$ En efecto, por un lado, resulta que «distintas normas no pueden contradecirse unas a otras si pretenden validez para el mismo círculo de destinatarios; tienen que guardar una relación coherente, es decir, formar sistema»; y, de otro lado, sucede que «entre las normas que vengan al caso y las normas que -sin perjuicio de seguir siendo válidas- pasan a un segundo plano, hay que poder establecer una relación con sentido, de suerte que no se vea afectada la coherencia del sistema jurídico en su conjunto», Ibidem, pp. 328 y 333. Este planteamiento no parece hacerse cargo de la existencia de antinomias «en concreto» que no lo sean «en abstracto», que es justamente uno de los pilares de la ponderación. Sobre esa distinción vid. R. Guastini, «Principios de derecho y discrecionalidad judicial», trad. de P. Andrés, Jueces para la Democacia, $\mathrm{n}^{\mathrm{o}} 34,1999, \mathrm{p} .43$. 
rechos fundamentales en aquellas posiciones que, en síntesis, niegan la posibilidad de límites externos a los derechos mediante el expediente de considerar que éstos, en puridad, ya vienen perfectamente delimitados desde un texto constitucional coherente; una posición «coherentista» que, como mínimo, resulta difícil de sostener en el marco de Constituciones pluralistas dotadas de principios y derechos tendencialmente contradictorios, que plantea asimismo dificultades ante los fenómenos de indeterminación y que, a la postre, conduce a una extensión de las potestades normativas de limitación ${ }^{14}$. Probablemente, esta última es también una consecuencia del planteamiento de Habermas.

Pero Habermas parece finalmente encontrar un lugar al Tribunal Constitucional en el marco de su proyecto político. Siguiendo la conocida exposición de J.H. Ely ${ }^{15}$, el Tribunal aparece ahora como un «defensor de la democracia deliberativa», que en una «comprensión republicana ha de operar en el sentido de que el proceso de producción de normas se efectúe en las condiciones de una política deliberativa, que son las que fundan legitimidad» ${ }^{16}$. Desde esta perspectiva, «el Tribunal Constitucional sólo puede conservar su imparcialidad si resiste a la tentación de cubrir su ámbito de interpretación con juicios valorativos de tipo moral» o con empresas de dirección política; su función ha de circunscribirse a garantizar «las condiciones procedimentales de la génesis democrática de las leyes, empezando por las estructuras de comunicación... siguiendo por las efectivas oportunidades de que pueden hacerse oir las voces desviantes y de que se puede hacer uso concreto y efectivo de los derechos de participación...» ${ }^{17}$. La tensión entre la democracia y las garantías constitucionales pretende ser así cancelada: los jueces no están para enmendar la obra del legislador, sino para garantizar que éste sea democrático.

Ahora bien, este programa presenta algunas dificultades y las presenta de modo especial en el caso de Habermas, cuya concepción de la democracia deliberativa no es precisamente formal, ni se mantiene en las fronteras liberales de unos derechos subjetivos de defensa. Porque, aceptando que la ley sea la expresión de la democracia deliberativa y que la función de la justicia constitucional consista en ganrantizar las condiciones de esa democra-

\footnotetext{
${ }^{14}$ No puedo extenderme aquí en estos aspectos, pero alguno abordé en mis Estudios sobre derechos fundamentales, Debate, Madrid, 1990, pp. 153 y ss.

${ }^{15}$ Democracy and Distrust. A Theory of Judicial Review, Harvard University Press, Cambridge Mass., 1980. Con razón indica R. Gargarella que suele existir una coincidencia entre la concepción deliberativa de la democracia y las propuestas de Ely, La justicia frente al gobierno, citado, p. 161.

${ }^{16}$ J. Habermas, Facticidad y validez, citado, p. 348 y s.

${ }^{17}$ Ibidem, p. 338.
} 
cia y no los «contenidos políticos» que de ella derivan, aún queda una cuestión fundamental por resolver, que es determinar hasta dónde llegan tales condiciones y, por tanto, las facultades de un control de constitucionalidad. Creo que Nino lo vio con claridad. Tras afirmar que «lo único que la mayoría no tiene legitimidad para decidir es la restricción de las condiciones y presupuestos que hacen del procedimiento democrático un mecanismo apto para encontrar soluciones correctas», añadía, sin embargo, que «esto puede tener una interpretación muy restringida o una interpretación bastante amplia» ${ }^{18}$. Y es que, efectivamente, si entendemos que requisitos de la democracia deliberativa y en consecuencia de la ley son que se cumpla el procedimiento parlamentario y que no se coaccione al diputado que vota, pero también que el elector tenga pleno acceso a la información y que pueda participar sin restricciones y en pie de igualdad con todos los ciudadanos, si entendemos que es también condición de la democracia la garantía de un nivel aceptable de existencia, de acceso a los bienes materiales y a la cultura, etc., entonces resulta que, en verdad, condiciones de la democracia son casi todas las prescripciones constitucionales que diseñan un modelo social: los derechos civiles que garantizan la autonomía individual, los de participación que hacen del sujeto un ciudadano activo y, por qué no, también los derechos económicos, sociales y culturales (que, por cierto, en la Constitución española se formulan expresamente como principios optimizables) que proporcionan el sustrato material indispensable para el ejercicio de la autonomía y de la participación. Con lo cual el propósito restrictivo en gran parte se esfuma y la justicia constitucional recobra toda su competencia sobre el conjunto de la normativa constitucional, desde aquella que directamente regula el ejercicio de la democracia hasta la que pretende juridificar la política, pasando desde luego por aquella otra que diseña una cierta forma de organización social. Entonces, una vez más, la irremediable sombra de la ponderación hace acto de presencia.

En resumen, Habermas parece abogar por un sistema de justicia constitucional distinto al que hoy conocemos, tanto en Europa como en Estados Unidos, un sistema alternativo que, como sabemos, últimamente está ganando adeptos. Porque, efectivamente, de un lado, Habermas se muestra un firme partidario de que el control abstracto de las leyes no salga de los con-

\footnotetext{
${ }^{18}$ «Puede tener una interpretación restringida si pensamos que el papel de los jueces debe limitarse a verificar si se dieron las condiciones procedimentales del debate y de la decisión democrática. Pero yo no creo que deba ser así, pues la validez de una decisión mayoritaria depende de muchas cosas. Depende de cuestiones tales como la existencia de una relativa igualdad en los recursos para participar en ese debate democrático, del acceso a la educación...», C.S. Nino, «La filosofía del control judicial de constitucionalidad», Revista del Centro de Estudios Constitucionales, $\mathrm{n}^{\circ} 4,1989$, p. 87.
} 
fines del legislativo; únicamente in extremis parece aceptar un esquema de Tribunal Constitucional, si bien subrayando que en ese caso la revisión judicial «sólo conduzca al rechazo de normas, pero no a encargos al legislador, razones pragmáticas y de política jurídica» ${ }^{19}$. De otra parte, por lo que se refiere al «control concreto» a través del recurso de amparo o de la cuestión incidental ${ }^{20}$, Habermas propone renunciar a la más poderosa técnica hoy utilizada en defensa de los derechos fundamentales y de los principios materiales de la Constitución para confiar dicha tarea a un Tribunal concebido más bien como la cúspide de la justicia ordinaria, que se encarga de la «unificación y coherentización del derecho» ${ }^{21}$ en los términos de una teoría de la interpretación guiada por el respeto a la ley y por la búsqueda de la famosa unidad de solución correcta. Finalmente, coronando todo el sistema, la atribución a la justicia constitucional de una función rigurosamente circunscrita al mantenimiento de los cauces participativos y de las reglas de formación de la voluntad legislativa, sin penetrar nunca en el recinto de los contenidos normativos a través de argumentos valorativos. En suma, un modelo de justicia constitucional «autocontenido» que, salvando algunas distancias, recuerda al propuesto por Kelsen y que seguramente reponde a unas preocupaciones análogas. La cuestión es si el constitucionalismo de nuestros días admite semejante propuesta.

\section{El sentido político del modelo kelseniano de Tribunal Constitucional.}

Aunque pueda parecer paradójico escuchando las cautelas que expresa Habermas y cuantos ven en la justicia constitucional un riesgo para las prerrogativas del legislador, así como el renacimiento de un incontrolable Derecho natural que cada cual interpreta a su manera, lo cierto es que, al menos en Europa, el modelo de Tribunal Constitucional es el invento de un positivista convencido y, sobre todo, de un defensor a ultranza del legislador democrático frente al activismo judicial y frente a la autonomía del Gobierno.

El contexto de la Europa de los años 30 explica la opción kelseniana y seguramente la opción posterior de las Constituciones alemana e italiana. Dicho contexto venía caracterizado por dos notas fundamentales: el fracaso del Tribunal Constitucional («Staatsgerichtshof») de la República de Wei-

${ }^{19}$ J. Habermas, Facticidad y validez, citado, p. 335.

${ }^{20}$ Dicho sea de paso, la cuestión de inconstitucionalidad no forma parte del control concreto, sino abstracto. Es concreto sólo en el sentido de que se formula en el curso de un proceso particular, pero es abstracto porque desemboca en una declaración general sobre la constitucionalidad de la norma dudosa.

${ }^{21}$ Ibidem, p.313. 
mar como tribunal de conflictos entre órganos estatales, un fracaso que desde luego obedeció más a motivos políticos que de técnica jurídica y que de hecho culminó en el famoso pleito entre Prusia y el Reich, uno de los primeros triunfos del nacionalsocialismo; y, segundo, el creciente activismo de los jueces ordinarios en el control de la ley ${ }^{22}$. Por lo que se refiere al primer aspecto, la historia es conocida: tras el «golpe de Estado» contra Prusia en 1932, el Tribunal, de acuerdo con su carácter de juez del caso cocreto, se niega a determinar en vía abstracta cuáles son las medidas lícitas que se pueden tomar al amparo del art. 48 de la Constitución. Ante el estado de excepción dictado por von Papen, el Tribunal adopta una solución de compromiso: los ministros prusianos seguían representando al Land, pero los comisarios asumían sus funciones ${ }^{23}$. Poco después Hindenburg dejará sin ninguna competencia a los antiguos ministros, Hitler disuelve el Parlamento de Prusia y el Tribunal no volverá a funcionar.

Por lo que se refiere al segundo aspecto, tan sólo hay que recordar que será en Weimar cuando llegue a su apogeo la reacción antilegalista y judicialista del Derecho libre: el juez se convierte en el mediador entre el Derecho y una supuesta conciencia popular, pudiendo incluso dictar sentencias contra legem $^{24}$. El Congreso de constitucionalistas de Münster en 1926 encontrará la justificación ideal para el desarrollo de ese control difuso: el principio de igualdad consagrado en el art. 109 de la Constitución, de manera que curiosamente será la doctrina jurídica conservadora la que comience a exigir la igualdad de la ley y no sólo ante la ley. Como observa Volpe $^{25}$, se habían sentado las bases para que, en el marco de una Constitución democrática, pudiera desarrollarse una instancia de control «aristocrática», que por lo demás tampoco se sentía necesariamente vinculada a la Constitución. La jurisprudencia alemana de los años 30 pone de relieve que el control jurisdiccional de la ley fue realizado como un examen de la «justicia» o justificación de la ley a partir de parámetros extraconstitucionales, como la «naturaleza de la cosa» o la «conciencia jurídica de la comunidad $\gg^{26}$.

${ }^{22}$ Vid. G. Volpe, L'ingiustizia delle leggi. Studi sui modelli di Giustizia Costituzionale, Giuffrè, Milano, 1977, pp.99 y ss. y 165 y ss.

${ }^{23}$ Vid. P. Cruz Villalón, La formación del sistema europeo de control de constitucionalidad (1918-1939), C.E.C., Madrid, 1987, pp. 259 y ss.

${ }^{24} \mathrm{He}$ tratado el tema en Ideología e interpretación jurídica, Tecnos, Madrid, 1987, pp. 35 y ss.

${ }^{25} \mathrm{G}$. Volpe, L'Ingiustizia delle leggi, citado, pp. 106 y ss.

${ }^{26}$ Una buena exposición del panorama de la época en la Introducción de E. Garzón Valdés a la compilación Derecho y filosofía, Alfa, Barcelona, 1985. 
Seguramente es esta experiencia la que en buena medida explica que el diseño constitucional de Kelsen no pierda nunca de vista ni la primacía de la ley ni las prerrogativas del legislador, y de hecho el opúsculo de 1931 en respuesta a $\mathrm{Schmitt}^{27}$ es un permanente alegato en favor del Parlamento frente al Jefe del Estado, pero también frente a la judicatura. Es más, sustrayendo toda competencia de control a la jurisdicción ordinaria, Kelsen configura un Tribunal que expresamente forma parte del poder legislativo y que, sobre todo, ha de actuar de manera tal que reduzca al mínimo la irremediable dimensión subjetiva o creativa que tiene todo órgano, sea legislativo o judicial. En el Tribunal, escribe Kelsen, «está ausente casi por completo...la libre creación que caracteriza a la legislación. Mientras que el legislador no está vinculado a la Constitución más que con respecto al procedimiento y solamente de forma excepcional respecto al contenido de las leyes..., la actividad del legislador negativo, de la jurisdicción constitucional, está, por el contrario, absolutamente determinada por la Constitución... se trata principalmente de aplicación y sólo en una débil medida de creación del Derecho» ${ }^{28}$.

Un aspecto que me parece capital para comprender esta propuesta kelseniana de justicia constitucional es la rigurosa exclusión de su esfera de competencia de todo lo que tiene que ver con hechos o intereses concretos, tanto de aquellos que tuvo en cuenta el legislador, como de aquellos otros que contempla el juez ordinario. En palabras de Gascón, «el rasgo definidor del sistema kelseniano residía en la rigurosa exclusión del conocimiento de hechos por parte del juez de constitucionalidad; su tarea quedaba así rigurosamente circunscrita a un juicio de compatibilidad lógica entre dos enunciados normativos perfectamente cristalizados, pero carentes de cualquier referencia fáctica, la Constitución y la ley» ${ }^{29}$. Y no es que Kelsen no fuese consciente de que la defensa de los derechos fundamentales hubiera requerido juicios concretos y no abstractos ${ }^{30}$; es que consideraba que un Tribunal

${ }^{27}$ H. Kelsen, ¿Quién debe ser el defensor de la Constitución?, Estudio preliminar de G. Gasió, trad. y notas de R.J. Brie y supervisión de E. Bulygin, Tecnos, Madrid, 1995.

${ }^{28} \mathrm{H}$. Kelsen, «La garantía jurisdiccional de la Constitución (la justicia constitucional)(1928), en Escritos sobre la democracia y el socialismo, edición de J. Ruiz Manero, Debate, Madrid, 1988, p.131.

${ }^{29}$ M. Gascón, «La Justicia Constitucional: entre legislación y jurisdicción», en Revista Española de Derecho Constitucional, $\mathrm{n}^{\circ}$ 41, 1994, p.64.

${ }^{30}$ En la segunda edición de la Teoría pura del Derecho, trad. de R.J. Vernengo, UNAM, México, 1986, Kelsen reconoce que «sólo cuando el individuo tiene el poder jurídico de suscitar la eliminación particular o general de la ley que por su contenido lesiona la igualdad o la libertad constitucionalmente reconocidas, el derecho o libertad fundamental constituye un derecho subjetivo del individuo», pero añade que «obligar jurídicamente a un órgano legislativo colectivo a no dictar leyes inconstitucionales es ya casi imposible por motivos técnicos, y de hecho no se impone tal obligación», p. 155 y s. 
respetuoso con el legislador no podía desarrollar un género de actividad que irremediablemente había de interferir en el ámbito de discrecionalidad legislativa. Como es sabido, el autor austriaco distingue en toda norma una dimensión aplicadora o reproductora de la norma superior y un momento de libre creación, pero todo parece indicar que este segundo momento, que responde a una siempre parcial indeterminación de la norma superior, se hace presente justamente a través de los hechos o intereses que valora el órgano inferior (el legislador ante la Constitución y el juez ordinario ante la ley). Por eso, el Tribunal queda excluido de la consideración de ese segundo momento, de manera que su función debe limitarse al control de la dimensión reproductora, esto es, de lo que efectivamente está determinado.

La insistencia en que el juicio de constitucionalidad se separe o haga abstracción de los hechos o intereses concretos permitiría decir con terminología actual que el Tribunal Constitucional kelseniano se ocupa sólo de los discursos de fundamentación, no de los discursos de aplicación ${ }^{31}$ o, lo que puede ser casi lo mismo, se ocupa de las reglas, no de los principios. En efecto, salvo las normas que especifican con total precisión sus condiciones de aplicación, todas las demás aparecen en sí indeterminadas, son aplicables sólo prima facie y depende de otras normas su adecuación definitiva al caso concreto. Pero esas normas que son aplicables prima facie y que, por tanto, aparentemente entran en conflicto con otras normas, no delatan ninguna incoherencia en el sistema. Por tanto, no es de ellas de las que había de encargarse el Tribunal, sino de las verdaderas incoherencias que se sitúan en el plano abstracto del discurso de validez o fundamentación. En suma, el Tribunal Constitucional kelseniano se mueve exclusivamente en esta última esfera, no en la de aplicación; se mueve en el campo de lo determinado, no en el de lo indeterminado. La indeterminación de la Constitución es el campo de la competencia legislativa, no de la judicial.

Este empeño en que el Tribunal Constitucional limite su actividad a lo que de determinado tiene la ley respecto de la Constitución, sin interferir en el ámbito de discrecionalidad del legislador, así como en excluir de su competencia todo discurso aplicativo en el que no se ventile la validez de las normas, sino sólo su preferencia circunstancial en el caso concreto, es lo que seguramente explica el rechazo kelseniano a la presencia de principios o claúsulas materiales en el seno de la preceptiva constitucional. Como escribe Rubio, hay en Kelsen «una repugnancia a admitir la vinculación del legislador a los preceptos no puramente organizativos de la Constitución, a

${ }^{31}$ Vid. Günther, K., «Un concepcto normativo de coherencia para una teoría de la argumentación jurídica», trad. de J.C. Velasco, Doxa, n $^{\text {17 }} 17-18,1995$, pp. 274 y ss. 
aceptar la predeterminación del contenido material de la ley» ${ }^{32}$. Pero no sólo eso: hay también una repugnancia a que, por encima de la ley, tales preceptos no puramente organizativos puedan ser tomados en consideración en los discursos de aplicación del Derecho mediante algo así como lo que hoy llamamos ponderación. En este sentido, cabe decir que la jurisdicción constitucional kelseniana se basaba ante todo en una concreta idea de Constitución, que es seguramente el aspecto que hoy más se ha transformado; una idea de Constitución como norma preferentemente formal, de competencia y procedimiento y sólo hasta cierto punto (Kelsen lo repite siempre) de contenido. Claramente, pone en guardia frente a ese riesgo que hoy es para muchos una espléndida realidad: lo que hoy llamamos principios «pueden jugar un papel extremadamente peligroso precisamente en el campo de la justicia constitucional. Podrían interpretarse las disposiciones de la Constitución que invitan al legislador a someterse a la justicia, la equidad, la igualdad, la libertad, la moralidad, etc. como directivas relativas al contenido de las leyes. Esta interpretación sería evidentemente equivocada... en ese caso el poder del tribunal sería tal que habría que considerarlo simplemente insoportable $»^{33}$.

En resumen, creo que el modelo kelseniano de justicia constitucional pretende expresar el máximo nivel de compatibilidad que es posible alcanzar entre dos ideas o criterios que son tendencialmente contradictorios, el de constitucionalidad y el de supremacía de la ley o, dicho de otro modo, el único sistema respetuoso con la tradición legalista del Derecho europeo una vez que la Constitución ya no se concibe en términos meramente retóricos. La configuración del Tribunal como un legislador negativo, la exclusión de los juicios aplicativos sobre casos concretos en que una ley pudiera verse postergada por algún precepto constitucional, la eliminación de las claúsulas indeterminadas y prácticamente de todo parámetro de constitucionalidad que no sea organizativo o procedimental, la idea de juicio abstracto o de compatibilidad lógica en el que sólo se valoren los escasos aspectos de la ley en los que ésta aparece determinada por la Constitución, son todas cautelas al servicio de las prerrogativas del legislador. Si cabe decirlo así, el sistema norteamericano está diseñado en favor de la supremacía judicial y de los derechos naturales frente al legislador; el sistema kelseniano, en cambio, supone un acto de desconfianza frente a los jueces ordinarios y de restablecimiento de la supremacía del Parlamento ante la actividad libre de los

${ }^{32}$ F. Rubio, «Sobre la relación entre el Tribunal Constitucional y el Poder Judicial en el ejercicio de la jurisdicción constitucional», en Revista Española de Derecho Constitucional, $\mathrm{n}^{\circ}$ 4, 1982, p.40.

${ }^{33}$ H. Kelsen, «La garantía jurisdiccional de la Constitución», citado, p. 142 y s. 
jueces. Ni Kelsen ni la Constitución austriaca de 1920 llegaron a concebir una norma generadora de derechos y obligaciones capaces de imponerse al legislador mediante una garantía judicial; la ley es el horizonte normativo máximo tanto para los jueces como para los ciudadanos, pues la Constitución opera en otro plano, en el plano «interno» de los órganos estatales y su garantía corresponde a un legislador especial, ajeno a las consideraciones políticas o discrecionales propias del Parlamento y ajeno también a la protección de derechos o intereses concretos.

Este modelo kelseniano será el que sirva de referencia a la justicia constitucional europea posterior a la segunda gran guerra, pero sólo en apariencia. Salvo el aspecto estructural de jurisdicción concentrada y algunos otros de carácter procesal, los actuales Tribunales Constitucionales responden más bien al esquema norteamericano de la judicial review ${ }^{34}$. Luego tendremos oportunidad de examinar algunas de esas transformaciones, pero tal vez el elemento más decisivo que expresa el abandono de la óptica kelseniana, el primero y el que más poderosamente llama la atención, se cifra en el contenido mismo del documento constitucional, que ha dejado de ser una norma sólo organizativa o procedimental para convertirse en una norma principial o rematerializada. Y, en segundo lugar, unido a lo anterior, la apertura de la justicia constitucional a los discursos aplicativos, a la resolución de casos concretos, lo que supone tanto que el Tribunal Constitucional deja de ser un juez «abstracto», como que los Tribunales ordinarios dejan de encarnar una justicia de mera legalidad para covertirse también en una justicia de constitucionalidad. Precisamente, esa apertura explica y, a mi juicio, hace inevitable la técnica de la ponderación que más tarde intentaremos explicar y que de un modo u otro rechazan tanto Habermas como Kelsen. A partir de ahí, la justicia constitucional de nuestros días entra en abierta pugna con la tradición legalista y con el absoluto respeto a la discrecionalidad del Parlamento que inspiró la primera contrucción europea de un Tribunal Constitucional.

\section{Las Constituciones de principios}

Como es sabido, la llamada «rematerialización» constitucional es un fenómeno generalmente aplaudido, que para algunos significa nada menos que la prueba palmaria de la reconciliación entre el Derecho y la moral de la modernidad ${ }^{35}$. Sin embargo, desde el punto de vista de las relaciones en-

${ }^{34}$ Sobre esto llama la atención E. García de Enterría, «La posición jurídica del Tribunal Constitucional en el sistema español: posibilidades y perspectivas», en Revista Española de Derecho Constitucional, $\mathrm{n}^{\circ}$ 1, 1981, p. 46.

${ }^{35}$ Ya advertí que no nos ocuparíamos aquí de este problema, que he intentado tratar en mi Constitucionalismo y positivismo, citado, pp.49 y ss. 
tre el legislador y la justicia constitucional, la incorporación de un amplio catálogo de valores, principios y derechos fundamentales tiene unos efectos devastadores que Zagrebelsky anuncia de forma rotunda: «la ley, un tiempo medida de todas las cosas en el campo del derecho, cede así el paso a la Constitución y se convierte ella misma en objeto de mediación» ${ }^{36}$.

Desde la perspectiva de la discrecionalidad, los principios presentan un rostro jánico. De un lado, y por mucha fe que se tenga en la argumentación racional, parece que la aplicación de principios comporta mayores riesgos de subjetividad valorativa que la aplicación de reglas. Sin embargo, de otra parte que es la que ahora más interesa, lo que parecen hacer los principios constitucionales es justamente cercenar la discrecionalidad del legislador. En el esquema del positivismo kelseniano la Constitución era fundamentalmente una Constitución de reglas formales, de manera que allí donde éstas no resultaban concluyentes o sencillamente aparecían como irrelevantes por su falta de contenido material se abría una amplia discreción legislativa no fiscalizable por ningún tribunal. En el esquema del constitucionalismo contemporáneo, en cambio, el sistema queda por así decirlo saturado mediante los principios, hasta el punto de que puede afirmarse que ningún problema o conflicto jurídico más o menos serio dejará de encontrar alguna orientación de sentido en la amplia panoplia de principios; con la particularidad de que estos principios, que antes han limitado la libertad política del legislador, se muestran depués como dúctiles instrumentos en manos del juez. La conclusión puede formularse así: la rematerialización de la Constitución a través de los principios supone un desplazamiento de la discrecionalidad desde la esfera legislativa a la judicial; bien es verdad que no se trata ya de la misma discrecionalidad, y la diferencia es esencial: la del legislador ha sido siempre una discrecionalidad inmotivada, mientras que la del juez pretende venir domeñada por una depurada argumentación racional.

En el fondo, lo que se ha producido es una distorsión de aquel modelo jerárquico tan firmemente diseñado por Kelsen: la Constitución ya no es sólo la norma suprema dirigida a condicionar de forma directa la labor legislativa y aplicable por los jueces únicamente a través del tamiz de la ley, sino que es la norma suprema que pretende proyectarse sobre el conjunto de los operadores jurídicos a fin de configurar en su conjunto el orden social. Como escribe Guastini, la función política de las Constituciones puede entenderse de dos formas: bien como límite al poder, bien como instrumento de modelación del orden social; generalmente, en la primera acepción se considera que las normas constitucionales se dirigen a los órganos supre-

${ }^{36}$ G. Zagrebelsky, El Derecho dúctil (1992), trad. de M. Gascón, con epílogo de G. PecesBarba, Trotta, Madrid, 1995, p. 40. 
mos del sistema, mientras que en la segunda se sugiere su extensión al conjunto de los órganos y en especial a los jueces; asimismo es típico que esta última concepción sea asumida por textos de un denso contenido material, mientras que la primera se correspondería con documentos breves y preferentemente formales ${ }^{37}$. Pues bien, si la Constitución kelseniana se mostraba ante todo como límite al poder, las actuales Constituciones principialistas asumen de forma resuelta la función de modelar el conjunto de la vida social, y por eso las relaciones entre legislación y jurisdicción ya no pueden presentarse de manera estrictamente jerárquica, sino de un modo más complejo que tampoco puede calificarse de simétrico: las decisiones del legislador siguen vinculando al juez, pero sólo a través de una interpretación constitucional de principios que efectúa este último ${ }^{38}$. La jurisprudencia ya no bebe en las fuentes constitucionales a través de la ley, sino que lo hace directamente, sobre todo en aquellas fuentes que incorporan los principios sustantivos y derechos fundamentales.

Siguiendo el lúcido análisis de Fioravanti ${ }^{39}$, asistimos a una convergencia de las dos tradiciones del constitucionalismo revolucionario: la norteamericana, que concibe la Constitución como norma fundamental de garantía y que proporciona la idea de que las leyes del Estado pueden y deben ser juzgadas desde una instancia superior, aunque desde esa instancia se renuncie a diseñar el sentido de la acción política del Gobierno; y la francesa, que ve en la Constitución una norma directiva fundamental, y que aporta la idea más sustancialista según la cual los poderes públicos han de perseguir ciertos fines de acuerdo con el modelo social querido por la soberanía popular, aunque tal modelo carecise de hecho de tutela judicial en virtud de una cierta interpretación de la separación de poderes y de la supremacía de la ley. La primera tradición conduce a la doctrina del gobierno limitado, mientras que la segunda sostiene la doctrina de los deberes del gobierno. Pero la combinación de ambas representa la más vigorosa afirmación del constitucionalismo frente a la omnipotencia y a la autonomía política del legislador;

${ }^{37}$ R. Guastini, «Specificità dell'interpretazione costituzionale?», en Analisi e Diritto, 1996, p. 170. Un alcance semejante tiene la distinción de E.W. Böckenförde entre el entendimiento de la Constitución como ordenamiento-marco y su concepción como orden jurídico fundamental de la comunidad en su conjunto, Escritos sobre Derechos Fundamentales, trad. de J.L. Requejo e I. Villaverde, Verlagsgesellschaft, Baden-Baden, 1993, p. 137.

${ }^{38}$ En palabras de L. Ferrajoli, «la sujeción del juez a la ley ya no es, como en el viejo paradigma positivista, sujeción a la letra de la ley, cualquiera que fuese su significado, sino sujeción a la ley en cuanto válida, es decir, coherente con la Constitución», Derechos y garantías. La ley del más débil, Introducción de P. Andrés, trad. de P. Andrés y A. Greppi, Trotta, Madrid, 1999, p.26.

${ }^{39}$ M. Fioravanti, Los derechos fundamentales. Apuntes de historia de las Constituciones, Presentación de C. Álvarez, trad. de M. Martínez Neira, Trotta, Madrid, 1996, pp. 127 y ss. 
frente a la omnipotencia porque, como es obvio, la Constitución como norma de garantía impone un control externo, y frente a la autonomía porque la Constitución como norma directiva pretende imponer a lo largo de amplias esferas de la decisión política qué objetivos corresponde perseguir. Una justicia constitucional que opere a partir de documentos que incorporen ambas tradiciones «destruye el dogma liberal-estatalista de la fuerza absoluta de la ley, y crea así una situación, inconcebible para la doctrina decimonónica, en la que la validez de las normas del Estado está como suspendida, en el sentido de que depende de un juicio de conformidad con la constitución y, en definitiva, con una cierta interpretación de la constitución y de los principios constitucionales» ${ }^{40}$.

Conviene subrayar la importancia que para la justicia constitucional tiene la confluencia de esas dos tradiciones y, consiguientemente, la incorporación de principios, derechos y directivas a un texto que se quiere con plena fuerza normativa. Porque ahora esas claúsulas materiales no se presentan sólo como condiciones de validez de las leyes, según advirtió Kelsen de forma crítica. Si únicamente fuese esto, el asunto sería transcendental sólo para aquellos órganos con competencia específica para controlar la ley, lo que en verdad no es poco. Sin embargo, la vocación de tales principios no es desplegar su eficacia a través de la ley -se entiende, de una ley respetuosa con los mismos- sino hacerlo de forma directa e independiente. Con lo cual la normativa constitucional deja de estar «secuestrada» dentro de los confines que dibujan las relaciones entre órganos estatales, deja de ser un problema exclusivo a resolver entre el legislador y el Tribunal Constitucional, para asumir la función de normas ordenadoras de la realidad que los jueces ordinarios pueden y deben utilizar como parámetros fundamentales de sus decisiones.

Hemos dicho que las Constituciones principialistas de nuestros días asumen la función de modelar el conjunto de la vida social, pero ¿cómo y en qué sentido lo hacen?. Parece que no como una decisión categórica de un grupo o ideología que, desde una filosofía política homogénea, diseña un marco unívoco y cerrado de convivencia; no se trata, para entendernos, de Constituciones comunistas o fascistas, ni siquiera de documentos claramente trasformadores o conservadores. Tampoco se trata en sentido propio de pactos o contratos donde se alcancen puntos indiscutibles mediante distintas aportaciones y recíprocas cesiones; aunque unos preceptos puedan identificarse como de «derechas» y otros como de «izquierdas», todos forman un conjunto unitario con idénticas pretensiones de validez y con la misma vocación ordenadora de la vida social, por encima y con independencia

\footnotetext{
${ }^{40}$ Ibidem, p. 129.
} 
del programa gubernamental de la mayoría. Aquí creo que hay que darle la razón a Zagrebelsky: la Constitución pluralista no es ni un mandato ni un contrato y, por eso, ni la teoría de la interpretación de la ley ni la del contrato resultan satisfactorias; no hay voluntad constituyente que pueda ser tratada como intención del legislador, ni siquiera de unas partes que llegan al acuerdo. Lo que hay son «principios universales, uno junto a otro según las pretensiones de cada parte, pero faltando la regulación de su compatibilidad, la solución de las “colisiones"y la fijación de los puntos de equilibrio» ${ }^{41}$.

Me parece que esto es particularmente cierto en el caso de la Constitución española, cuyo título de Constitución del consenso, muy celebrado en los comienzos de su andadura ${ }^{42}$, tal vez deba ser matizada. No significa ese consenso un simple acuerdo de mínimos sobre las reglas del juego democrático, tampoco la incorporación de contenidos materiales siempre claros y precisos, aun cuando pudieran ser el fruto de mutuas cesiones, sino que viene a expresar la plasmación de lineas o principios ideológicos heterogéneos y a veces tendencialmente contradictorios que presentan, sin embargo, una idéntica pretensión de validez y de conformación de la sociedad; un ejemplo paradigmático creo que es el derecho a la educación del artículo 27, tantas veces llevado ante el Tribunal Constitucional, cuyos nueve primeros apartados (del décimo y de su desarrollo es mejor no hablar) encarnan los más diversos y opuestos planteamientos de filosofía educativa. Tal vez la cuestión no tendría más importancia si las claúsulas materiales de la Constitución se interpretasen sólo en el sentido de que autorizan a las sucesivas mayorías a realizar sus propias políticas. Pero no es así: en virtud del carácter directamente normativo de la Constitución, dichas claúsulas aparecen como pretensiones de inmediata eficacia, con independencia y por encima de la ley. No cabe hablar en tales condiciones de un orden o sistema de valores, cerrado y jerarquizado, sino más bien de un pluralismo o «desorden» de principios que entran en juego simultáneamente y que, en la medida en que se hallan presentes en los discursos de aplicación -y no sólo en los juicios de validez abstracta- han de ser irremediablemente ponderados por el juez.

${ }^{41}$ G. Zagrebelsky, «Storia e costituzione», en Il futuro della Costituzione, a cura de G. Zagrebelsky, P.P. Portinaro y J. Luther, Einaudi, Torino, 1996, pp. 76 y ss. Tal vez esto explique por qué el originalismo y la extraordinaria importancia que en Estados Unidos se concede a las intenciones del constituyente, resultan en cambio de muy escasa relevancia en Europa. Sobre ello llama la atención E. Alonso García, «La jurisprudencia constitucional», en Revista del Centro de Estudios Constitucionales, 1, 1988, p.208.

${ }^{42}$ Vid., por ejemplo, G. Peces-Barba, La Constitución española de 1978. Un estudio de Derecho y política, con la colaboración de L. Prieto, F. Torres, Valencia, 1981, pp. 13 y ss. 
Desde esta perspectiva, creo que es cierto que la teoría de la interpretación positivista - tal vez no la más lograda de sus aportaciones, dicho sea de paso- resulta insuficiente ante una Constitución de principios. En particular, la técnica de la subsunción no es aplicable a los principios y derechos constitucionales que presentan de forma abierta el supuesto de hecho o la condición de aplicación; mejor dicho, no es que no sea aplicable, es que sucede con frecuencia que un mismo caso resulta subsumible en dos derechos o principios tendencialmente contradictorios, como ocurre con la libertad de expresión y el derecho al honor, con la libertad en general y la seguridad colectiva o con el derecho de propiedad y los derechos sociales. Y tampoco resultan operativos los conocidos criterios de resolución de antinomias; no lo son claramente el jerárquico y el cronológico, pero, como veremos, tampoco el de especialidad. Algo semejante puede decirse de los principios entendidos como mandatos de optimización, singularmente con los derechos sociales que expresamente se configuran en España como «principios rectores de la política social y económica (Capítulo III del Título I): la Constitución no fija con precisión el umbral mínimo de su cumplimiento y, por tanto, el juez carece de una consecuencia jurídica concluyente para aplicar al caso; o ésta se deja a la total discrecionalidad legislativa como en general se viene haciendo, pero entonces tales principios no pueden considerarse normas constitucionales; o es el juez quien establece por sí mismo ese umbral mínimo por debajo del cual empieza a operar la garantía, pero entonces es el juez y no la norma constitucional quien lo hace ${ }^{43}$. Las Constituciones de principio reclaman, pues, nuevas técnicas interpretativas, técnicas que, a mi juicio, no entran en pugna con los postulados básicos del positivismo -aquí fundamentalmente con el de la discrecionalidad-pero que son ajenas a la teoría del Derecho construida por el positivismo.

\section{Algunas técnicas de la interpretación constitucional; en particular, la ponderación}

Ciertamente, son muchas las diferencias que separan la práctica de los actuales Tribunales Constitucionales y también de los tribunales ordinarios que aplican la Constitución respecto del modelo que fuera diseñado por Kelsen, y aquí sólo procede una sumaria referencia. De entrada, y por lo que se refiere a la jurisdicción constitucional, creo que ha desaparecido aquella rigurosa exclusión de los hechos, de los conflictos e intereses subyacentes a la ley y al caso concreto de la esfera de conocimiento del Tribunal, así como también la neta distinción entre el juicio de constitucionalidad reserva-

${ }^{43}$ Ultimamente he tratado este tema con mayor extensión en «Diez argumentos sobre los principios», en Ley, principios, derechos, Dykinson, Madrid, 1998, pp. 52 y ss. 
do a un órgano especialísimo y el juicio de legalidad reservado a la jurisdicción ordinaria. Aunque, como herencia de otra época, no es infrecuente que el Tribunal despache algunas inadmisiones o desestimaciones recordando que su función se circunscribe al enjuiciamiento de normas, con abstracción de los hechos, enjuiciamiento cuyo único parámetro ha de ser además la Constitución y no su propia opinión sobre la mejor interpretación de la ley, y aunque incluso algún precepto de la LOTC se hace eco de esa tradición, lo cierto es que irremediablemente el Tribunal Constitucional enjuicia hechos e interpretaciones legales, sobre todo como es lógico en los recursos de amparo y en la cuestiones de inconstitucionalidad ${ }^{44}$. Con lo cual, a la postre, aquí el Tribunal no sólo es garante de la Constitución, sino también de la solución más adecuada al caso; no vigila sólo la validez, sino también la justicia de la decisión. Por lo demás, es absolutamente evidente que la jurisdicción ordinaria aplica la Constitución, y no sólo cuando plantea la cuestión, sino precisamente cuando no lo hace.

Sin embargo, el gran hallazgo de la jurisprudencia constitucional es lo que suele conocerse con el nombre de juicio de razonabilidad y que representa el método característico para la aplicación de las genuinas normas constitucionales, y muy particularmente para la aplicación del principio de igualdad ${ }^{45}$. Existe discriminación cuando «la desigualdad del tratamiento legal sea injustificada por no ser razonable ${ }^{46}$; para que exista violación del principio de igualdad es preciso que el tratamiento desigual «esté desprovisto de una justificación objetiva y razonable» ${ }^{47}$. Conviene subrayar que la exigencia de justificación del tratamiento legal no sólo ha de aportar alguna razón lícita que pueda ser usada por el legislador, o en su caso por el juez, sino que ha de ser además razonable a juicio del Tribunal: «no basta con que el fin perseguido sea constitucionalmente lícito... sino que han de ser razonables y proporcionados $»^{48}$. Sobre el criterio de la proporcionalidad volveremos más adelante, pero ¿cuál es la fuente de lo razonable?.

La Constitución proclama la igualdad, pero obviamente no establece (sino sólo por aproximación y discutida vía de ejemplo, art. 14) cuándo una determinada circunstancia fáctica puede o debe ser tomada en consideración para operar una diferenciación normativa; esto es algo que primero hace el legislador y luego el Tribunal Constitucional, pero no con base en la

\footnotetext{
${ }^{44}$ Vid. sobre el particular M. Gascón, «La Justicia Constitucional: entre legislación y jurisdicción», citado, pp. 66 y ss.

${ }^{45}$ Un análisis del tratamiento jurisprudencial de la igualdad en A. Ruiz Miguel, «La igualdad en la jurisprudencia del Tribunal Constitucional», en Doxa, nº19, 1996, pp. 39 y ss.

${ }^{46}$ STC 34/1981.

${ }^{47}$ STC 33/1983.

${ }^{48}$ STC $144 / 1988$
} 
Constitución que nada dice de forma concluyente, sino a partir de su propio razonamiento acerca de lo que merece ser tratado de manera igual o desigual. Parece evidente, por tanto, que «no es en la Constitución, sino fuera de ella, en donde el juez ha de buscar el criterio con el que juzgar sobre la licitud o ilicitud de la diferencias establecidas por el legislador», y ese otro lugar resulta ser algo tan evanescente como la conciencia jurídica de la comunidad, «sólo en la conciencia jurídica de la comunidad puede buscar el juez el criterio que le permita pronunciarse sobre la razonabilidad o irrazonabilidad de la obra del legislador...lo que significa sin duda una politización de la justicia» ${ }^{49}$; en otras palabras, en la aplicación de la igualdad no puede haber nada parecido a la subsunción porque no existe propiamente una premisa mayor constitucional. En realidad, la apelación a la razonabilidad en que consiste el juicio de igualdad nos remite a un esfuerzo de justificación racional de la decisión ${ }^{50}$ y encierra un conflicto entre principios, pues actúa siempre a partir de igualdades y desigualdades fácticas parciales que postulan tratamientos tendencialmente contradictorios, cada uno de los cuales puede alegar en su favor uno de los subprincipios que componen la igualdad: tratar igual lo que es igual, y siempre habrá alguna razón para la igualdad pues todos los seres humanos tienen algo en común, y desigual lo que es desigual, y siempre habrá también alguna razón para la desigualdad pues no existen dos situaciones idénticas. Luego si hay razones en favor y razones en contra será preciso ponderarlas o sopesarlas y ver cuál de ellas resulta proporcionalmente más fuerte.

En efecto, una versión más depurada de la genérica razonabilidad nos la ofrece el principio o máxima de la proporcionalidad, que es el método habitualmente utilizado por los Tribunales, constitucionales o no, para resolver la colisión circunstancial entre derechos fundamentales o, en general, el conflicto entre derechos y otros bienes constitucionales. Su importancia es capital por cuanto la proporcionalidad es la prueba que debe superar toda medida restrictiva de un derecho constitucional ${ }^{51}$, desde la decisión gubernamental que prohibe una manifestación en la calle ${ }^{52}$ a la resolución judicial que ordena un cierto examen o intervención corporal en un imputado ${ }^{53}$, pasando por la ley penal que establece una determinada privación de libertad

${ }^{49}$ F. Rubio, «La igualdad en la jurisprudencia del Tribunal Constitucional. Introducción», en Revista Española de Derecho Constitucional, n ${ }^{\circ} 31,1991$, pp.30 y ss.

${ }^{50}$ Vid. A. Calsamiglia, «Sobre el principio de igualdad», en J. Muguerza y otros, El fundamento de los derechos humanos, Debate, Madrid, 1989, p.109.

${ }^{51} \mathrm{He}$ tratado este punto en mis Estudios sobre derechos fundamentales, citado, pp. 139 y ss.

${ }^{52}$ STC 66/1995.

${ }^{53}$ STC 207/1996. 
como castigo de cierta conducta ${ }^{54}$. En pocas palabras, la prueba de la proporcionalidad se descompone en cuatro elementos, que deberán ser sucesivamente acreditados por la decisión o norma impugnada: primero, un fin constitucionalmente legítimo como fundamento de la interferencia en la esfera de los derechos; segundo, la adecuación o idoneidad de la medida adoptada en orden a la protección o consecución de dicho fin; tercero, la necesidad de la intervención o, lo que es lo mismo, del sacrificio del derecho, mostrando que no existe un procedimiento menos gravoso o restrictivo; y finalmente, la proporcionalidad en sentido estricto que supone ponderar entre daños y beneficios, es decir, acreditar que existe un cierto equilibrio entre los beneficios que se obtienen a través de la medida limitadora y los daños o lesiones que de la misma se derivan para el ejercicio del derecho, pues, en palabras de Alexy, «cuanto mayor es el grado de la no satisfacción o de afectación de un principio, tanto mayor tiene que ser la importancia de la satisfacción del otro» ${ }^{55}$.

La proporcionalidad o ponderación ${ }^{56}$ no supone establecer algo así como un orden jerárquico entre los distintos bienes o derechos, pues, salvo que la prioridad haya sido establecida de forma directa por la Constitución, hemos de suponer que «en abstracto» todos ellos tienen el mismo peso o importancia. Por eso, la ponderación se resuelve en una exigencia de proporcionalidad que implica establecer un orden de preferencia relativo al caso concreto. Como explica Guastini ${ }^{57}$, la técnica del «bilanciamento» o de la ponderación es la típica para la resolución de los conflictos entre los principios constitucionales, donde no cabe aplicar las reglas tradicionales de resolución de antinomias. Lo característico de la ponderación es que con ella no se logra una respuesta válida para todo supuesto, no se obtiene, por ejemplo, una conclusión que ordene otorgar preferencia siempre a la seguridad pública sobre la libertad individual o a los derechos civiles sobre los sociales, sino que se logra sólo una preferencia relativa al caso concreto que no escluye una solución diferente en otro caso; se trata, por tanto, de una jerarquía móvil que no conduce a la declaración de invalidez de unos de los

${ }^{54}$ STC 55/1996. Un comentario a ésta y a las sentencia citadas en las dos notas precedentes, en las que el Tribunal Constitucional termina por perfilar claramente el principio de proporcionalidad, en I. Perello, «El principio de proporcionalidad y la jurisprudencia constitucional», en Jueces para la Democracia, $\mathrm{n}^{\circ} 28,1997$, pp.69 y ss.

${ }_{55}$ R. Alexy, Teoría de los derechos fundamentales(1986), trad. de E. Garzón Valdés, C.E.C., Madrid, 1993, p.161.

${ }^{56}$ Muchas veces estas expresiones se usan como sinónimas. En realidad, parece que la ponderación representa la última fase del principio de proporcionalidad, es decir, lo que hemos llamado proporcionalidad en sentido estricto.

${ }^{57}$ R. Guastini, «Specificità dell`interpretazione costituzionale?», citado, pp. 177 y ss. 
bienes o derechos constitucionales en conflicto, sino a la preservación de ambos, por más que inevitablemente ante cada conflicto sea preciso reconocer primacía a uno u otro.

El principio de proporcionalidad y, sobre todo, el subprincipio llamado de proporcionalidad en sentido estricto en que se resuelve la ponderación de bienes han sido ampliamente criticados como una espita abierta al decisionismo y a la subjetividad judicial, crítica a la que, como vimos, se sumaba Habermas; «la limitación de las libertades a partir de los valores sólo es posible mediante una ponderación de valores en la que cualquier postura puede sostenerse ${ }^{58}$. No creo que la objeción esté por completo fundada: no es cierto que la ponderación sea un método vacío, ni que pueda conducir a cualquier consecuencia, pues, si bien no garantiza una y sólo una respuesta para cada caso práctico, sí nos indica qué es lo que hay que fundamentar para resolver un conflicto o colisión, es decir, hacia dónde ha de moverse la argumentación, a saber: la justificación de un enunciado de preferencia (en favor de un principio u otro, de un derecho o de su limitación) en función del grado de sacrificio o afectación de un bien y del grado de satisfacción del bien en pugna. La razón práctica no es un monopolio de los discursos sobre la validez que quede suspendida en los discursos de aplicación; al contrario, la ponderación supone imponer una carga de argumentación que justifique la postergación circunstancial de un principio válido ${ }^{59}$. Como dice Alexy, las objeciones de irracionalidad o subjetivismo «valen en la medida en que con ellas se infiera que la ponderación no es un procedimiento que, en cada caso, conduzca exactamente a un resultado. Pero no valen en la medida en que de ellas se infiera que la ponderación no es un procedimiento racional o es irracional» ${ }^{60}$.

Ahora bien, que la ponderación no equivalga a irracionalidad no significa también que su resultado sea el fruto de la mera aplicación de normas constitucionales o, dicho de otro modo, que represente un ejercicio de racionalidad no supone que sus conclusiones vengan impuestas por la preceptiva constitucional; es una operación racional, pero una operación que en lo esencial se efectúa sin «red normativa», a partir de valoraciones en las que no tiene por qué producirse un acuerdo intersubjetivo. La Constitución,

${ }^{58}$ I. de Otto, «La regulación del ejercicio de los derechos y libertades», en L. Martín-Retortillo e I. de Otto, Derechos fundamentales y Constitución, Civitas, Madrid, 1988, p. 117. Para la doctrina alemana, donde la cuestión es ampliamente discutida, vid. R. Alexy, Teoría de los derechos fundamentales, citado, pp. 157 y ss; también J.C. Gavara, Derechos fundamentales y desarrollo legislativo, C.E.C., Madrid, 1994, pp. 287 y ss.

${ }^{59}$ Vid. Günther, K., «Un concepto normativo de coherencia para una teoría de la argumentación jurídica», citado, p.284.

${ }^{60}$ R. Alexy, Teoría de los derechos fundamentales, citado, p. 157. 
como es obvio, no establece ningún orden jerárquico de valores, bienes o derechos y decidir que el sacrificio circunstancial de uno de ellos «merece la pena» desde la perspectiva de la satisfacción de otro entraña sin duda una valoración; valoración en la que -aunque no se quiera- pesará la importancia que cada individuo concede a los respectivos bienes en conflicto, así como su propia «cuantificación» de costes y beneficios en el caso concreto ${ }^{61}$. Pero esta es una valoración que en parte ya viene hecha por una autoridad precedente (por ejemplo, el legislador ${ }^{62}$ ) y que es o puede ser sustituida por la del juez de constitucionalidad. En la ponderación, en efecto, hay siempre un conflicto entre bienes constitucionales, pero hay también una ley (o una decisión administrativa o judicial) que ya ha tomado postura, que ya ha valorado y que, como se verá, puede ser eliminada o postergada por una valoración sucesiva que se apoya en un ejercicio de racionalidad, pero propiamente no en un mandato constitucional. En cierto modo, el Tribunal Constitucional parece confesarlo cuando, a propósito de un recurso de amparo en defensa de la libertad de expresión, dice que el juez «no estaba obligado a otorgar preferencia a uno u otro de los derechos en juego», pero sí a motivar y razonar su decisión sobre la base del reconocimiento de un conflicto ${ }^{63}$. Luego la obligación en cuestión parece derivar, no tanto de una normativa constitucional que nada dice sobre el particular, sino de una exigencia suplementaria de argumentación racional.

Que el de proporcionalidad es un concepto sumamente dúctil que reclama un amplio ejercicio de valoración creo que no ofrece dudas, pero puede quedar mejor ilustrado con el examen comparativo de alguna jurisprudencia constitucional, concretamente la relativa a la proporcionalidad de las penas. Como es conocido, que las penas sean proporcionadas a la gravedad de los delitos es una vieja aspiración de la filosofía ilustrada y garantista que, sin embargo, la Constitución no ha recogido de forma expresa. Ello no ha impedido al Tribunal Constitucional considerar que dicha exigencia debe

${ }^{61}$ Por eso, como observa Guastini, esta tarea comporta una doble discrecionalidad. «Es discrecional la operación consistente en instituir una jerarquía de valores entre los principios implicados, y es asimismo discrecional la operación consistente en combinar el valor relativo de tales principios a tenor de los diversos casos prácticos», «Principios de derecho y discrecionalidad judicial», citado, p. 44.

${ }^{62}$ En realidad, el legislador no puede resolver el conflicto entre principios de un modo definitivo, pues eliminar esa colisión con carácter general requeriría postergar en abstracto un principio en beneficio de otro y, con ello, establecer por vía legislativa una jerarquía entre preceptos constitucionales que, sencillamente, supondría asumir un poder constituyente. Sin embargo, el legislador sí puede establecer regulaciones que privilegien o respondan a cierto principio en detrimento de otro, y son esas regulaciones, que entrañan una primera valoración, las que constituyen el objeto del juicio de ponderación.

${ }^{63}$ STC 104/1986. 
ser observada por un legislador penal que, a la postre, cuando impone una pena de prisión está limitando cuando menos la genérica libertad personal del art. 17, sin contar eventualmente la lesión de otros derechos, como la libre expresión, la participación política, etc.; aunque, eso sí, el control ha de ejercerse con extraordinaria cautela, pues resulta imprescindible mantener «la potestad exclusiva del legislador para configurar los bienes penalmente protegidos, los comportamientos penalmente reprensibles, el tipo y la cuantía de las sanciones penales, y la proporción entre las conductas que pretende evitar y las penas con las que intenta conseguirlo». El juicio de proporcionalidad corresponde, pues, al legislador, de manera que una hipotética fiscalización sólo es concebible en casos verdaderamente extraordinarios; en concreto, cuando se produzca un «desequilibrio patente y excesivo o irrazonable» que lesione «el valor fundamental de la justicia en un Estado de Derecho y de una actividad no arbitraria y respetuosa con la dignidad de la persona» ${ }^{64}$.

Con este bagaje doctrinal, que representa una de las expresiones más restrictivas del juicio de proporcionalidad, el Tribunal Constitucional ha rechazado la violación del criterio comentado incluso en algunos supuestos que razonablemente se prestaban a una solución distinta: por ejemplo, consideró que no era desproporcionada la pena de 12 años, 4 meses y un día para un almacenista que se apropió de carne de vacuno congelado propiedad de cierta Comisaría de Abastos, y ello a pesar de que el propio juzgador solicitaba la conmutación de la pena por otra más equitativa; lo que equivale a decir, en un juego de palabras ininteligible, que una pena que se juzga excesiva puede resultar al mismo tiempo proporcionada ${ }^{65}$. Del mismo modo, no se ha encontrado desmesurada una pena superior a dos años de cárcel para quienes de forma reincidente pescaron cangrejos en tiempo de veda ${ }^{66}$. Finalmente, el Tribunal tampoco halló motivo de reproche a la pena de 6 meses a un año para los que se nieguen a la práctica de la prueba (inculpatoria, por cierto) de alcoholemia, y ello aunque esa sanción resulta superior a la prevista para el hecho mismo de conducir bajo la influencia de benidas alcoholicas; algo que, como denunció un magistrado disidente, provoca un resultado paradójico: «si, después, prueba que no condujo bajo la influencia de bebidas... sufrirá una pena superior a la que le hubiera correspondido si acepta el hecho de conducir bajo dicha influencia, lo cual no parece ser conforme a la lógica ${ }^{67}$. Sin embargo, recientemente se ha decidido que

\footnotetext{
${ }^{64}$ STC 55/1996.

${ }^{65}$ STC 65/1986.

${ }^{66}$ STC 53/1994.

${ }^{67}$ STC 161/1997.
} 
la pena de 7 años de prisión para el delito de colaboración terrorista puede ser $-\mathrm{y}$, al parecer, lo fue en el caso enjuiciado- desproporcionada ${ }^{68}$.

No procede comentar ahora los distintos pronunciamientos de esta última sentencia, a mi juicio tan acertada en el fallo como desafortuna en la argumentación, pero lo cierto es que inaugura una doctrina que de llevarse hasta sus últimas consecuencias - de lo que sospecho no hay peligro alguno- representaría la apertura de una frontera inédita en el control de constitucionalidad de la ley al expropiar una de las competencias más asentadas e indiscutidas en la historia del Parlamento, como es el ejercicio del ius puniendi del Estado ${ }^{69}$. Este giro jurisprudencial puede ser interpretado de muchas maneras, incluso desde la perspectiva de un contexto de descubrimiento que aquí tenemos vedado, pero tan sólo quiero destacar un aspecto. Ya he dicho que, en mi opinión, el juicio de proporcionalidad no sólo no es inútil, sino que representa una pieza clave en la protección de los derechos y en la resolución de los conflictos constitucionales; tampoco debería ser capaz de conducir a cualquier resultado, aunque tal vez resulte algo optimista pensar que garantice uno solo correcto. Es cierto que la proporcionalidad permite el desarrollo de distintas argumentaciones, pero me parece que, si se lee atentamente, lo que produce cierta impresión de arbitrariedad no son los razonamientos singulares en que se apela a esa proporcionalidad, sino la consideración conjunta de todos ellos. A lo mejor, al final, el primer imperativo kantiano sigue siendo la mejor garantía y ello tiene una traducción jurídica inmediata: el respeto al precedente y, sobre todo, al autoprecedente $^{70}$. En suma, si se pretende que una Constitución de principios goce de una protección jurisdiccional, la valoraciones son irremediables. Lo deseable es que, dentro de lo que cabe, siempre fuesen las mismas.

Pero desde la perspectiva de la justicia constitucional y de sus relaciones con el legislador el problema no reside sólo en que la ponderación reclame algún tipo de valoración, sino en que abre el juicio de constitucionalidad a los discursos aplicativos, con dos importantes consecuencias. La primera es que, si bien en nombre de la proporcionalidad puede declararse la

\footnotetext{
${ }^{68}$ STC de 22 de julio de 1999.

${ }^{69}$ En síntesis, el razonamiento de la sentencia es el siguiente: 1 ) la conducta $\mathrm{X}$ (ceder espacios de propaganda electoral para emitir un mensaje de E.T.A.) se integra en el tipo penal de colaboración con banda armada; 2) dicho tipo es en principio irreprochable desde una perspectiva constitucional; 3) no obstante, la sanción aplicada a la conducta X resulta desproporcionada; 4) en consecuencia, el tipo delictivo es inconstitucional sólo en el sentido de que la pena mínima prevista es demasiado severa para todas las conductas que eventualmente puedan quedar comprendidas en el mismo.

${ }^{70}$ Vid. M. Gascón, La técnica del precedente y la argumentación racional, Tecnos, Madrid, 1993. Sobre el precedente en general vid. el no 6 de Ragion Pratica (1996), con trabajos de M. Taruffo, A. Aarnio, S. Eng, J. Marshall, A. Peczenik, R. Summers y M. Troper.
} 
invalidez de una ley, por lo común su juego se traduce en una desaplicación; esto es, en un reconocimiento de que, a pesar de que la ley es constitucional y pertinente al caso, debe sin embargo quedar desplazada en el concreto supuesto examinado. En principio, que ocurra una cosa u otra debe depender del tipo de antinomia que se entable entre la disposición enjuiciada y el derecho fundamental: si aquélla, en todas las hipótesis de aplicación posibles, resulta lesiva para el derecho, lo procedente es declarar su inconstitucionalidad; por ejemplo, si se estima que una ley punitiva establece una pena desproporcionada para la conducta tipificada, o si se juzgan también desproporcionadas las exigencias legales para el ejercicio de algún derecho. Al contrario, si la norma contempla supuestos de aplicación no lesivos para el derecho y otros que sí lo son, entonces la ponderación desemboca en la desaplicación; así, cuando un juez considera que, pese al carácter injurioso de una conducta y pese a resultar de aplicación el tipo penal, debe primar sin embargo el principio de la libertad de expresión, lo que hace es prescindir de la ley pero no cuestionar su constitucionalidad. Algo que, como ya se ha dicho, llega bastante más lejos de lo imaginado por Kelsen, pues implica la postergación circunstancial de una ley (y del principio constitucional que la sustenta, claro está) que se reconoce válida ${ }^{71}$.

La segunda consecuencia es que, al abrirse a los discursos aplicativos, la ponderación se ha convertido en un formidable instrumento de justicia constitucional en manos del juez ordinario; como es obvio, éste no puede verificar un control de validez de las leyes, pero sí moverse con relativa libertad meced a la ponderación. Detrás de toda regla late un principio y los principios son tendencialmente contradictorios; por ejemplo, detrás de cada precepto del Código civil (o casi) encontramos bien el principio de autonomía de la voluntad, bien el derecho de propiedad, pero frente a ellos un sistema principialista como el nuestro proporciona el derecho al trabajo, a la salud, a la vivienda, al medio ambiente, la «función social» de la propiedad, etc. En suma, la técnica de los principios y con ella la ponderación son aplicables siempre y no sólo en presencia de enunciados dotados de ciertas características, porque siempre está al alcance del juez transformar en principios las reglas que sustentan la posición de cada parte.

Que resulte viable un control de racionalidad de las leyes equivale a decir que la racionalidad constituye un requisito exigible en la producción normativa, como ya lo es en las tareas de aplicación del Derecho. Y además

${ }^{71}$ Esto ocurre porque la colisión entre principios o derechos constitucionales es, en terminología de Günther, una colisión externa y no interna, es decir, una colisión que aparece y ha de ser resuelta en el discurso de aplicación, no en el de fundamentación, «Un concepto normativo de coherencia para una teoría de la argumentación jurídica», citado, pp. 279 y ss. 
esto es algo que encuentra explícito apoyo en la Constitución, cuyo artículo 9.3 establece «la interdicción de la arbitrariedad de los poderes públicos», esto es, no sólo de la Administración y de los jueces, sino también del legislador. Ciertamente, esa interdicción ha de hacerse compatible con la discrecionalidad política del legislador, lo que tal vez explique la notable prudencia que ha mostrado el Tribunal Constitucional cuando se ha visto llamado a enjuiciar una presunta arbitrariedad de la ley, pero en todo caso ese precepto constitucional permite un desarrollo jurisprudencial de amplias consecuencias, y basta pensar en una posible extrapolación de la doctrina ya consolidada en materia de control de la Administración, posibilidad por la que algunos abogan decididamente ${ }^{72}$. En suma, existe una sola noción de racionalidad y ésta es aplicable tanto a la legislación como a la jurisdicción ${ }^{73}$, aunque en aquélla aún no haya encontrado la misma virtualidad que en ésta. Cuestión distinta, sobre la que luego volveremos, es que ello obligue a revisar la sacrosanta teoría de la soberanía del legislador.

Finalmente, la idea de que la Constitución, más que un límite al legislador, es una norma que directamente ordena amplias esferas de las relaciones sociales presenta un corolario implícito, y es que la defensa de la Constitución no sólo comporta una legislación negativa que le diga al legislador sólo aquello que no puede hacer, sino que reclama también una legislación positiva capaz de suplir, complementar o corregir al Parlamento en la tarea de hacer realidad el programa constitucional. En cierto modo, las sentencias interpretativas y manipulativas responden a esta filosofía. Las primeras parten de una distinción entre la disposición legislativa y la norma o resultado de la interpretación realizada sobre aquélla ${ }^{74}$ que, de entrada, parece suponer una intromisión en el ámbito de la Justicia ordinaria, pues implica que el Tribunal Constitucional determina qué interpretación de un enunciado legal resulta conforme a la Constitución o, al contrario, cuál debe excluirse por incompatible con la misma; y, naturalmente, de establecer la «interpretación constitucional» de un enunciado a presentar la «mejor interpretación» del mismo sólo hay un paso. Con la particularidad de que, al ser las sentencias del Tribunal Constitucional algo más que precedentes autorizados, operando directamente en el ordenamiento a título de legislación, ocurre que esas interpretaciones adquieren la fuerza misma de una disposición legislativa. Dicho de otro modo, las mayores o menores posibilidades her-

\footnotetext{
${ }^{72}$ Vid. T.R. Fernández, De la arbitariedad del legislador, Civitas, Madrid, 1998.

${ }^{73}$ Vid. M. Atienza, Contribución a una teoría de la legislación, Civitas, Madrid, 1997, pp. 95 y ss.

${ }^{74}$ Una reciente contribución que toma como hilo conductor la mencionada distinción entre disposición y norma es la de F.J. Ezquiaga, La producción jurídica y su control por el Tribunal Constitucional, Tirant lo Blanch, Valencia, 1999.
} 
meneúticas toleradas o queridas por la ley ya no están a disposición de la justicia ordinaria, sino que quedan cercenadas merced a la labor del Tribunal, y esto equivale a legislar. Más lejos llegan las llamadas sentencias manipulativas, sobre todo en su versión «aditiva», mediante las que el Tribunal no sólo opera sobre las interpretaciones de una disposición, sino que en cierto modo lo hace directamente sobre ésta última, añadiendo a la misma aquello que omitió y constitucionalmente no debió omitir el legislador ${ }^{75}$.

\section{Esquema de conclusiones}

Indicábamos al comienzo que la tesis legalista atribuida al positivismo podía ser interpretada bien en clave descriptiva o de teoría del Derecho, bien en clave prescriptiva o de política jurídica. Desde la primera perspectiva, parece evidente que el legalismo es hoy un enfoque equivocado, al menos si lo entendemos en los términos tradicionales que hacían del legislador el señor supremo del Derecho. Y la verdad es que la existencia de una Constitución y de una justicia constitucional como las que acaban de ser descritas es sólo un síntoma y acaso no el más importante de la crisis de la ley: el mantenimiento de la secular pugna con la potestad reglamentaria que hoy adquiere tintes más complejos porque, si bien ya no se discute el principio de jerarquía ni se defienden ámbitos exentos en favor del Ejecutivo, la normativa administrativa, sin embargo, se extiende cada vez más en la amplísima esfera del Estado social donde la ley abdica de sus competencias; la pérdida del valor de la unicidad u homogeneidad de la ley como consecuencia de las autonomías territoriales dentro del Estado, capacitadas para producir leyes diferentes sobre las mismas materias, así como del imparable proceso de «transferencia de soberanía» a la Unión Europea; el desarrollo de nuevas fuentes sociales del Derecho, lo que unido al fenómeno de la desregulación conduce una vez más a la postergación de la decisión legislativa $^{76}$. Todo ello, unido a la actividad (o al activismo dirán algunos) de la justicia constitucional llevada a cabo por jueces especiales y ordinarios hace hoy irreconocible la imagen del legislador omnipotente. Lo cual, por cierto, creo que tampoco significa un cambio de ubicación de la soberanía, tampoco significa que la ley haya cedido su privilegiado lugar a la Constitución, a los jueces o a las instituciones europeas; refleja tan sólo un pano-

${ }^{75}$ Sobre la técnica de las sentencias interpretativas y manipulativas vid. M. Gascón, «La Justicia Constitucional: entre legislación y jurisdicción», citado, pp. 70 y ss.; también G. Parodi, «Lacune e norme inespresse nella giurisprudenza costituzionale» y M.C. Redondo, «Incostituzionalità e lacune normative», ambos en Struttura e dinamica dei sistemi giuridici, a cura de P. Comanducci e R. Guastini, Giappichelli, Torino, 1996, pp. 87 y ss.

${ }^{76}$ Vid. más ampliamente mi trabajo «Del mito a la decadencia de la ley. La ley en el Estado constitucional», en Ley, principios, derechos, citado, pp.24 y ss. 
rama mucho más complejo que en algunos aspectos recuerda al sistema de fuentes de la Edad Media. Como observa Zagrebelsky, «ya no puede pensarse en la Constitución como centro del que todo derivaba por irradiación a través de la soberanía del Estado en que se apoyaba, sino como centro en que todo debe converger; es decir, más bien como centro a alcanzar que como centro del que partir. La "política constitucional" mediante la cual se consigue ese centro no es ejecución de la Constitución, sino realización de la misma en uno de los cambiantes equilibrios en los que puede hacerse efectiva $\gg^{77}$.

En la realización de esa «política constitucional» de la que nos habla Zagrebelsky la justicia constitucional en su más amplia significación es una pieza clave. Frente a las cautelas y escrúpulos con que Kelsen abordó el diseño de una justicia constitucional respetuosa con la separación de poderes, con el principio de las mayorías y, en suma, con las prerrogativas del legislador, cautelas y escrúpulos que en gran parte nos recuerda Habermas, la realidad que cabe observar a partir de la sucinta exposición precedente parece alejarse de cualquier legalismo entendido como monopolio en la producción del Derecho. La aplicación judicial del Derecho se halla desde luego sujeta a normas, y a normas a veces muy restrictivas acerca de los supuestos y formas de la intervención, pero es potencialmente ilimitada en el sentido de que, desde el más resonante conflicto político a la más nimia actuación administrativa o incluso relación jurídico privada, no hay esfera en la que la preceptiva constitucional no tenga algo que decir; y son precisamente los jueces quienes lo dicen, empleando para ello delicadas técnicas interpretativas en las que la distancia que separa una argumentación racional a partir de la Constitución de una decisión subjetiva es con frecuencia demasiado tenue. La teoría del Derecho positivista ya no puede ser, por tanto, legalista porque la ley ya no es la única ni la suprema fuente del Derecho; conserva, sin duda, una gran importancia que no es preciso subrayar, pero ahora su función no es «crear» el sistema, sino «integrarse» en un sistema ya dado y en permanente renovación donde su palabra es sólo una de las que pueden pronunciarse, no la única, ni la última. Como escribe Böckenförde, si «los derechos fundamentales se mantienen como normas (objetivas) de principio y se desarrollan como tales, es inevitable la progresión continua hacia el Estado jurisdiccional de justicia constitucional» ${ }^{78}$.

Entendido en el segundo sentido, como una tesis prescriptiva defensora de la ley como fuente legítima o más legítima de creación de Derecho, ya he dicho que el legalismo no me parece un aspecto del positivismo, salvo si

\footnotetext{
${ }^{77}$ G. Zagreblesky, El Derecho dúctil, citado, p.14.

${ }^{78}$ E.W. Böckenförde, Escritos sobre derechos fundamentales, citado, p.135.
} 
se piensa en un positivismo ideológico que abandone la descripción para asumir funciones de persuasión moral o política. Por otra parte, aquí vienen a primer plano todas las discusiones acerca de si es bueno que exista una Constitución, de si ésta debe o no contener un amplio catálogo de derechos y de principios normativos, de si éstos deben hacerse valer en vía jurisdiccional y en qué forma, etc.; cuestiones todas ellas cuyo tratamiento excede de los propósitos de este trabajo. Con todo, creo que en el fondo la respuesta a estos interrogantes es política y depende en buena parte de la óptica subjetiva de quien trata de responderlos, sin excluir desde luego el diagnóstico de cada uno acerca del estado de la judicatura y de la legislatura.

Por mi parte, y sin prejuzgar cuál haya de ser el modelo más adecuado de justicia constitucional e incluso si ha de existir alguno en el plano del juicio abstracto de leyes o puede ser el propio Parlamento quien se autotute$l^{79}$, lo que sí creo es que la defensa de los derechos fundamentales frente a todos y, por supuesto, también frente al legislador representa una exigencia insoslayable del Estado de Derecho entendido como un Estado de garantías. Suscribo en este aspecto la opinión de Ferrajoli: una concepción material de la democracia, o sea, una concepción no meramente procidementalista ha de ser «garante de los derechos fundamentales de los ciudadanos y no simplemente de la omnipotencia de la mayoría» y esa garantía sólo puede ser operativa con el recurso a la instancia jurisdiccional ${ }^{80}$. Ahora bien, más allá de esto, decidir qué grado de protagonismo pueden tener los jueces, o ciertos jueces, en la legislación negativa o positiva a través de controles abstractos, es algo más discutible y que puede depender de otras consideraciones circunstanciales, como en primer lugar el juicio sobre la bondad de la rigidez constitucional, sin excluir tal vez las propias expectativas sobre el comportamiento de jueces y legisladores. Me parece que esta es una de las conclusiones de Comanducci cuando dice que «la interpretación "moral" de la Constitución abre la puerta a la discrecionalidad judicial (que, es cierto, siempre se halla presente, aunque puede ser limitada). Esto puede complacer a los progesistas, pero sólo a condición de que los jueces puedan ser progresistas. Es lo que habitualmente sucede hoy en gran parte de los Tribunales Constitucionales... Pero no está dicho que las cosas sean siem-

${ }^{79}$ Este último sistema puede parecer francamente inútil y reiterativo, aunque cabe pensar en algunas garantías suplementarias como las sugeridas por J.C. Bayón en su propuesta de constitucionalismo débil, «Diritti, democrazia, costituzione», en Ragion Pratica, $\mathrm{n}^{\circ}$ 10, p. 63 y s.; por ejemplo, que una ley que alterase la tabla de derechos hubiera de ser adoptada en dos votaciones sucesivas y separadas por una convocatoria electoral. Aunque, en verdad, esta previsión parece inscribirse más en el capítulo de la reforma constitucional que en el de su garantía.

${ }^{80}$ L. Ferrajoli, Derechos y garantías. La ley del más débil, citado, p.23 y s. 
pre así. Me parece en particular peligroso, en sede de aplicación de la Constitución, la técnica de la ponderación caso por caso de los principios incorporados al texto constitucional. La opción deliberada de no establecer una jerarquía explícita entre los principios al menos para clases de casos... comporta la atribución para el juez constitucional de un margen tan amplio de discrecionalidad que haga de él no sólo un colegislador, sino incluso, en alguinos casos, un coautor de la Constitución misma ${ }^{81}$. Los peligros de la ponderación en el caso concreto son sin duda reales, pero a mi juicio difícilmente eliminables si se acepta la vinculación directa y universal de los derechos fundamentales ${ }^{82}$.

Pero, hablando de legalismo, ha salido a relucir otra tesis positivista que también fue anunciada al principio del trabajo: la tesis de la discrecionalidad judicial. No parece que la discrecionalidad admita en los mismos términos la doble versión descriptiva y prescriptiva que hemos distinguido a propósito del legalismo, pues así como hay firmes partidarios de restaurar la supremacía del legislador, en la literatura reciente no es tan fácil oir voces en favor de la absoluta discrecionalidad del juez. Que los jueces desempeñen una función creadora de Derecho en el sentido fuerte de la expresión, que sus decisiones incorporen al menos una dimensión subjetiva o moral que va más lejos de lo previsto por el Derecho, que, como mínimo, a partir del material jurídico puedan sostener soluciones diferentes a propósito de los mismos problemas fácticos, son afirmaciones que básicamente se interpretan como verdaderas o falsas, no como ideales hacia los que se deba tender. Aun cuando pueda discutirse si un cierto grado de discrecionalidad resulta o no saludable para el funcionamiento del sistema jurídico, lo cierto es que la desvinculación del juez a la ley como tesis prespriptiva es algo que no se defiende desde el llamado Derecho libre ${ }^{83}$. En cualquier caso, que exista una Constitución de principios que todos puedan interpretar

${ }^{81}$ P. Comanducci, «Interpretazione della costituzione» en Assaggi di metaetica due, Giappichelli, Torino, 1998, p.122.

${ }^{82}$ Por otro lado, dice Moreso que la ponderación en los casos concretos, por ejemplo en los conflictos entre derechos fundamentales, no afecta a la regla de las mayorías, «Diritti e giustizia procedurale imperfetta» y «Sulla portata del vinculo preventivo», en Ragion Pratica, $\mathrm{n}^{\circ} 10$, pp.13 y ss. y 75 y ss. Tal vez la afirmación podría ser matizada: es cierto que aquí no está en juego la validez de la ley, pero el conflicto entre derechos o principios encubre un conflicto entre algún precepto legal -apoyado en cierto principio- y otro principio constitucional, lo que a la postre se traduce en la no aplicación de tal precepto legal; y esto me parece que lesiona el ferreo criterio de sometimiento del juez a la ley, uno de los corolarios del legalismo democrático.

${ }^{83} \mathrm{H}$. Kantorowicz, en efecto, llega a proponer sentencias arbitrarias, es decir, incontroladas e incontrolables desde la ley, «La lucha por la ciencia del Derecho» (1906), trad. de W. Goldschmidt en el volumen La Ciencia del Derecho, Losada, Buenos Aíres, 1949, pp.325 y ss. 
y que la justicia constitucional abrace la técnica de la ponderación o de las sentencias manipulativas, ¿es un síntoma del incremento de la discrecionalidad?.

Hay algunos indicios de que la respuesta puede ser negativa, de que, pese a las apariencias, los principios y su aplicación ponderativa reducen y no amplían la discrecionalidad. Así, y aunque el argumento pueda no ser de mucho peso, no deja de resultar significativo que los más empeñados defensores de la tesis de la unidad de solución correcta, como Dworkin, ilustren sus construcciones teóricas mediante los más complejos problemas constitucionales, en los que precisamente una jurisprudencia constructiva a partir de los principios viene a compensar el déficit de racionalidad de un Derecho de reglas o positivista ${ }^{84}$. Por otro lado, dice Habermas que la imagen que hoy tenemos del Derecho decimonónico como un sistema jurídico que podía aplicarse sin tener que recurrir a principios necesitados de una interpretación constructiva es sólo un «espejismo actual»», lo cual viene a sugerir que tanto con una Constitución de principios explícitos como con un sistema presidido por principios implícitos -al modo tal vez de los principios generales del Derecho- la situación no es muy diferente y que nuestra opinión al respecto, afirmadora de la discrecionalidad o, como es el caso del propio Habermas, negadora de la misma, no debe alterarse sustancialmente.

Creo que Habermas tiene en este punto algo de razón. Tanto si asumimos la tesis positivista de la discrecionalidad como si nos adherimos al género de interpretación constructiva defendida por el autor alemán, nuestra opinión no tiene por qué ser distinta, exista o no una Constitución abiertamente principialista; es más, algunos podrán pensar que la discrecionalidad de un sistema de reglas puede desaparecer merced a los principios. Por mi parte, como ya he avanzado, creo que los principios y derechos fundamentales desempeñan una función bifronte o de doble sentido. Trataré de explicarlo mejor. Básicamente, el positivismo es una teoría del Derecho sin teoría de la argumentación, de manera que la relativa indeterminación de las normas se resolvía a través de la discrecionalidad: discrecionalidad del legislador en primer lugar y, sometido a éste, discrecionalidad del juez, y por eso el Tribunal Constitucional kelseniano, siempre respetuoso con el legislador, sólo había de ocuparse de la dimensión reproductora o determinada de la norma inferior respecto de la superior. Pero, en este sentido, la presencia de principios en la Constitución ha venido a imprimir una mayor determinación frente al legislador, pues, por mucho que los principios suelan

${ }^{84}$ Vid. sobre el particular la reciente aportación de M. Iglesias Vila, El problema de la discreción judicial. Una aproximación al conocimiento jurídico, C.E.P.C., Madrid, 1999.

${ }^{85}$ J. Habermas, Facticidad y validez, citado, p. 325. 
calificarse y con razón de indeterminados, lo cierto es que ofrecen pautas o estándares normativos allí donde antes sólo existía la discrecionalidad política $^{86}$. Recurriendo al planteamiento de Moreso, tal vez pueda decirse que los principios son una «pesadilla» por su alto grado de indeterminación, pero que nos acercan al «noble sueño» en la medida en que introducen determinación en una esfera antes confiada a la discrecionalidad; con lo que quizás a la postre nos hallaríamos en ese lugar intermedio que es la «vigilia» ${ }^{87}$. Sea como fuere, la aplicación de principios reclama una teoría de la argumentación especialmente refinada que pueda intentar compensar su déficit de determinación.

Por eso, la pregunta que antes quedó planteada admite una doble respuesta: desde el punto de vista de su aplicación, los principios y la técnica de la ponderación pueden incrementar la indeterminación del Derecho y la discrecionalidad de un juez antes sometido sólo al imperio de la ley, y ello por las razones que indica Comanducci: por su mayor grado de vaguedad, por la ausencia de una moral común y porque en la ponderación falta una jerarquía estable y general entre los principios ${ }^{88}$. Pero desde el punto de vista del legislador sometido al control de constitucionalidad (abstracto o concreto), el mismo fenómeno parece tener justamente el efecto contrario: donde antes existía discrecionalidad política ahora se alzan los principios y, consiguientemente, la ponderación y sus cultivadores, los jueces, porque donde antes existía indeterminación ahora pretende existir determinación, aunque sea la que modestamente ofrecen los principios. Que ello suponga sustituir una discrecionalidad por otra, como pretende el legalismo menos refinado, o que, por el contario, signifique un avance decisivo del Estado de Derecho, de manera que en lugar de decidir el legislador simplemente «lo que quiere» ahora decida el juez «lo que debe», es algo que en buena parte depende de nuestra fe en las posibilidades y alcance de la argumentación jurídica.

\footnotetext{
${ }^{86}$ Este paradójico doble papel de los principios es observado también por Böckenförde. De un lado, en efecto, «el desarrollo de la eficacia objetiva de principio de los derechos fundamentales conduce así a una creciente pre-determinación de los contenidos indeterminados... aumenta progresivamente lo pre-establecido normativamente en y a partir de la Constitución»; y ello con la lógica consecuencia de que «la red de lo pre-establecido constitucionalmente se hace para el legislador no sólo más extensa, sino también más túpida; el legislador -respecto a su poder de configuración del Derecho- decae cada vez más en el papel de un poder reglamentario». Sin embargo, de otra parte, «dado que los pre-establecidos constitucionales son indeterminados, el Tribunal Constitucional se convierte, en su labor de concretización de su alcance, de modo específico, en el señor de la Constitución», Escritos sobre derechos fundamentales, citado, pp. 135 y ss.

${ }^{87}$ Vid. J.J. Moreso, La indeterminación del Derecho y la interpretación de la Constitución, C.E.P.C., Madrid, 1998, en particular el planteamiento sobre la justicia constitucional en pp. 233 y ss.

${ }^{88}$ P. Comanducci, «Principi giuridici e indeterminazione del diritto», en Assaggi di metaetica due, citado, p.95.
} 
Con todo, y cualquiera que sea esa fe en la argumentación jurídica, el panorama descrito no puede dejar de proyectarse sobre el modo tradicional de concebir legislación y jurisdicción. Desde la perspectiva de ese modelo, que es basicamente el aceptado por el positivismo, existiría un profundo divorcio entre la racionalidad legislativa y la racionalidad judicial: en la primera triunfan los fines u objetivos, según un esquema teleológico y consecuencialista, de manera que una buena ley es aquella que se propone buenos fines y es capaz de obtenerlos; mientras que la sentencia ha respondido siempre a una racionalidad deductiva o sistemática, en el sentido de que una buena sentencia o, mejor aún, una sentencia correcta es aquella cuya decisión se infiere de sus premisas y, en particular, de una premisa normativa. De ahí que los «considerandos» o la fundamentación sean indispensables en la sentencia y no lo sean en la ley ${ }^{89}$. Pues bien, el constitucionalismo basado en principios y derechos creo que estimula un esquema de racionalidad más compartido ${ }^{90}$. En primer lugar, porque es evidente que la ponderación de bienes y la técnica de la proporcionalidad no responden a un simple esquema lógico deductivo, requiriendo por parte del juez una racionalidad teleológica o lo que algunos llaman despectivamente un «mercado de valores». Y, por otra parte, si bien la ley no puede entenderse ni siquiera idealmente como una mera deducción de la preceptiva constitucional, resulta que tampoco puede entrar en contradicción con ella, y esto requiere efectuar un juicio acerca de su racionalidad normativa no muy diferente del que supone comprobar la legalidad de una sentencia; en cierto modo, el antiguo juicio externo o ético sobre la justicia de la ley se ha transformado en un juicio interno o sobre su validez, algo que ha de estar presente ante todo en la racionalidad legislativa, anticipo de la racionalidad judicial.

Estas consideraciones creo que nos conducen a una última conclusión: si en algo cambia el panorama jurídico tras una Constitución de principios garantizada a través de mecanismos jurisdiccionales, es precisamente en el papel que ha de asumir la argumentación o el razonamiento jurídico; y una teoría del Derecho no puede dejar de levantar acta de este fenómeno. Aun cuando se mantenga viva la tesis de la discrecionalidad y, con ello, se dé la razón a una idea central del positivismo, no puede olvidarse que este último descuidó el cada día más extenso capítulo de la argumentación. Como acabamos de ver, el positivismo consideró que allí donde finalizaba la deter-

${ }^{89}$ Vid. E. Bulygin, «Sentencia judicial y creación de Derecho» (1966), en C. Alchourron y E. Bulygin, Análisis lógico y Derecho, C.E.C., Madrid, 1991, p.356.

${ }^{90}$ En favor de una relativización de las diferencias entre racionalidad legislativa y judicial vid. también M. Atienza, Contribución a la teoría de la legislación, citado, pp. 98 y ss. 
minación del Derecho y aparecían los márgenes de indeterminación sencillamente se alzaba el vacío jurídico y la subjetividad de los operadores jurídicos; subjetividad que, en un marco legalista, correspondía desarrollar de forma primaria al Parlamento y, en un marco judicialista, a los jueces. Pero es ésta la imagen que difícilmente puede mantenerse en pie, pues, cualquiera que sea la fórmula técnica que distribuya las competencias entre ambos sujetos, lo que una Constitución de principios y derechos fundamentales ya no parece tolerar es que cuando aparece la autoridad del legislador calle la razón, ni que cuando finaliza la subsunción se abra paso la subjetividad. Si argumentar equivale en último término a justificar, el nuevo constitucionalismo encarna una exigencia de justificación o, mejor dicho, de mayor justificación: ya no basta apelar a la autoridad del órgano y al procedimiento -que es en sustancia lo que hacía el Tribunal Constitucional kelseniano-, sino que es preciso también acudir a los contenidos ${ }^{91}$. Y con esta extensión de la argumentación y, por tanto, de la justificación creo que se amplían las fronteras del Derecho y del Estado de Derecho en detrimento de la esfera más decisionista o política dominada por la libertad de configuración legislativa o por la intuición subjetiva del juez.

Para terminar, y aunque he prometido no ocuparme de este aspecto, procede advertir que ese saludable reforzamiento de la argumentación a que nos invita el constitucionalismo de principios no equivale a una feliz reconciliación del Derecho y la moral y, por tanto, creo que puede seguir manteniéndose la conocida tesis positivista de la separación. La idea del razonamiento jurídico como caso especial del razonamiento moral, al margen de que presente no pocas ambigüedades, no cancela la citada separación, ni desde la perspectiva de la dogmática constitucional ni, mucho menos, desde la óptica de una teoría del Derecho; de la imperfección del Derecho, técnica pero también moral, no escapa la argumentación ${ }^{92}$. Y, por cierto, los perfiles que presenta el actual debate acerca de quién debe tener la última palabra, si el legislador o los jueces, revelan o, al menos, son un indicio de que el problema central no consiste en determinar el órgano más indicado o mejor dotado para llevar a cabo ese ejercicio de común racionalidad, que sería -creo yo- lo que debería suceder si se confiase en que por la argumentación camina irremediablemente la moral correcta. Lo que se discute son más bien problemas ideológicos y de poder sobre el presupuesto de que los

${ }^{91}$ Vid. sobre estas distintas justificaciones M. Atienza, Derecho y argumentación, Universidad Externado de Colombia, Bogotá, 1997, pp. 34 y ss.

${ }_{92}$ Vid. sobre el particular A. García Figueroa, «La tesis del caso especial y el positivismo jurídico», ponencia presentada al IV Congreso hispano-italiano de Teoría del Derecho, Almagro, 1998 y publicada en Doxa, núm. 22, 1999, pp. 195-220. 
resultados de la racionalidad legislativa y de la racionalidad judicial no han de ser siempre los mismos o, dicho de otro modo, sobre el presupuesto de que el común sometimiento a la Constitución que se predica, no promueve necesariamente una única respuesta, ni jurídica ni moral; tal vez porque, junto al ejercicio de racionalidad que requiere una Constitución de principios, en la legislación y en la jurisdicción queda siempre un hueco para la decisión, para el acto de poder. 


\section{DOXA 23 (2000)}

